\title{
Hierarquia de Gênero e Iniqüidade em Saúde
}

\author{
JENI VAITSMAN *
}

\section{Princípios universais e hierarquia de gênero}

Se, por um lado, a questão da modernização, englobando processos de industrialização e urbanização, não é nova no debate teórico e político na América Latina, por outro, a temática da modernidade, implicando a conquista de direitos civis, políticos e sociais, coloca-se, nos anos 90 , como um dos pontos cruciais desse debate. Na cena latino-americana, além da exclusão de boa parte da população do mercado de consumo, os processos de modernização tampouco se fizeram acompanhar de instịtuições próprias garantindo a abrangência da modernidade. ${ }^{1}$

Essa característica do desenvolvimento latino-americano, que levou Lechner a perguntar se, nesse contexto, modernização e modernidade não seriam incompatíveis, tem duas implicações importantes. A primeira, e mais evidente, diz respeito à institu cionalização de práticas e normas que expressem um alcance abrangente dos direitos civis, políticos e sociais universais, ou seja, à conquista de autonomia e igualdade em sociedades de modernização excludente.

* Pesquisador adjunto da Escola Nacional de Saúde Pública, Fundaçāo Oswaldo Cruz.

1. N. Lechner, “A Modernidade e a Modernizaçāo Sāo Compatíveis? - O Desafio da Democracia Latino-Americana”, Lua Nova, $\mathrm{n}^{2} 21,1990$. 
A segunda implicação, que discutirei mais detidamente neste artigo, não é tão evidente e consiste em uma problematização da primeira, a partir de um olhar feminista: os princípios de igualdade e autonomia, que se desenvolveram como o eixo axiológico da modernidade ocidental, conformaramse historicamente como atributos do gênero masculino.

Refletir sobre essa apropriação do universal por uma das metades sexuais da espécie humana, pressupõe fazer uma crítica à categoria indivíduo que veio corporificar os valores fundamentais das sociedades que reconhecem os direitos civis, pólíticos e sociais típicos da modernidade. Meu ponto de partida é o argumento de que na gênese do indivíduo moderno não houve espaço para que a diferença sexual se expressasse de forma igualitária, traduzindo-se, ao contrário, por meio de uma dicotomia e uma hierarquia de gênero entre homens e mulheres.

Alguns dos determinantes históricos da construção social de gênero moderna encontram-se na configuração específica das relações sociais que forneceram o referencial para aquilo que autonomia e igualdade passaram a significar: as práticas correntes no mundo público da política e do mercado, ao qual as mulheres não tinham as mesmas condições de acesso que os homens.

Como já discuti em outro lugar, ${ }^{2}$ a construção da ordem social moderna, a institucionalização dos direitos civis, políticos e sociais implicou o reconhecimento legal de certas práticas sociais e a configuração de uma ordem simbólica fortemente marcada por valores individualistas que se contrapôs ao particularismo das sociedades tradicionais. ${ }^{3}$ Nesse sentido, Dumont ${ }^{4}$ procurou mostrar como o pensamento liberal que se desenvolveu a partir do século XVIII operou uma importante mudança nos valores ocidentais. Sobretudo a partir de Locke, ${ }^{5}$ a hierarquia deixou de ser vista como algo natural entre as pessoas, sendo, em lugar disso, e em extensão social cada vez mais abrangente, pensada a partir do princípio de que existe uma igualdade natural entre elas. Aos poucos, a desigualdade passou a ser considerada como algo decorrente do mundo social, resultado do esforço de

2. J. Vaitsman, Flexiveis e Plurais - Identidade, Casamento e Familia em Circunstâncias Pós-Modernas, Rio de Janeiro, Rocco, 1994.

3. Segundo Lukes, as quatro idéias-unidade do individualismo seriam as seguintes: dignidade humana, autonomia, autodesenvolvimento e privacidade. A primeira idéia corresponde à noçăo de igualdade e as três últimas à de liberdade. S. Lukes, Individualism, Londres, Basil Blackwell, 1983.

4. L. Dumont, Hommo Aequalis, Paris, Gallimard, 1977.

5. J. Locke, Segundo Tratado sobre o Governo, São Paulo, Ed. Abril, Col. Os Pensadores, 1978. 
cada indivíduo para apropriar-se das coisas da natureza. A desigualdade torna-se social, pensada como uma consequiência da propriedade, a qual, por sua vez, aparece como o resultado daquilo que mais evidentemente pertence ao indivíduo - seu corpo e seu esforço. Sendo a propriedade e a desigualdade vistas agora como resultado do trabalho de cada um, isto quer ao mesmo tempo dizer que as desigualdades começam também a ser representadas como derivadas de uma qualidade intrínseca às pessoas como indivíduos. Nesse processo, os valores hierárquicos que caracterizam as sociedades tradicionais vão sendo negados pelos valores igualitários que se tornaram característicos das sociedades burguesas modernas. ${ }^{6}$

A conformação dos princípios simbólicos individualistas que imprimiram o caráter de moderno à maioria das sociedades ocidentais é parte do desenvolvimento do capitalismo industrial. Ou seja, historicamente, a construção da modernidade ocorreu vinculada aos processos de modernização - implicando a urbanização, a expansão das atividades educacionais, administrativas, científicas e tecnológicas - ao modo como o indivíduo e o cidadão modernos, no bojo de tais processos, configuraram-se em cada contexto sócio-histórico específico.

A industrialização, que passou pela dicotomia entre público/privado, ou seja, entre o mundo do mercado e da política, por um lado, e o mundo da família, por outro, destituiu a unidade doméstica de seu caráter produtivo, produzindo-se ao mesmo tempo uma hierarquização entre práticas sociais produtivas/improdutivas e públicas/privadas. As atividades então definidas como oficialmente econômicas, ${ }^{7}$ produtivas, isto é, como trabalho, restringiram-se àquelas exercidas na esfera regida pelo princípio universalista do mercado. Ou seja, a esfera na qual o indivíduo livre podia concorrer para vender sua força de trabalho, seus produtos ou serviços. ${ }^{8}$

As mulheres foram definidas socialmente segundo os requisitos de um mundo público ao qual não tinham acesso, e com isso seu lugar permaneceu no mundo privado organizado pelos princípios particularistas e hierárquicos das relações adscritas a certos homens - como filhas e esposas -, e não em uma esfera pública definida pelos princípios universalistas e igualitários do mercado e, mais tarde, da cidadania. ${ }^{9}$

6. J. Vaitsman, Flexíveis e Plurais..., op. cit.

7. A crítica à idéia de "economia oficial” e às teorias que enfocam as relaçōes na família como nảo-econômicas foi desenvolvida por N. Fraser, Unruly Practices - Power, Discourse and Gender in Contemporary Social Theory, Minneapolis, University of Minnesota Press, 1989.

8. J. Vaitsman, Flexíveis e Plurais..., op. cit.

9. Idem. 
A concepção de que a igualdade entre os indivíduos se sustenta na essência universal que estes possuem enquanto donos de seu corpo e, conseqüentemente, de seu trabalho, fez com que as mulheres fossem excluídas da constituição do indivíduo e do cidadão enquanto categorias históricas. Com o capitalismo industrial e a instituição da família conjugal moderna formada idealmente por um pai provedor econômico e uma mãe dona de casa, a condição individual das mulheres definiu-se de tal forma que elas não detinham muito controle tanto de seu corpo quanto de seu trabalho: de seu corpo, uma vez que este não deixou de ser submetido a diferentes formas de coerção no interior mesmo do mundo privado; e de seu trabalho, porque este se tornou, oficialmente, uma atividade no interior da família, invisível, sem valor, definido como improdutivo e complemento subordinado do trabalho masculino.

O que é importante ressaltar é que a categoria indivíduo nascida com a modernidade nunca teve, de fato, uma abrangência universal, pois emergiu das práticas exercidas legitimamente apenas pelos homens na esfera pública: igualdade e autonomia transformaram-se em atributos do sexo masculino. ${ }^{10}$ Foi esta concepção patriarcal de indivíduo que fez com que, em várias partes do mundo moderno, os direitos de cidadania se restringissem inicialmente aos homens, permanecendo as mulheres casadas legalmente subordinadas aos maridos, ${ }^{11}$ seja na dimensão econômica, jurídico-política ou civil. Ao expressar-se socialmente por meio da dicotomia público e privado, a diferença sexual traduziu-se socialmente em hierarquia de gênero. Nesse processo descrito de forma típico-ideal as mulheres foram oficialmente excluídas das condições de acesso à igualdade e autonomia. Contudo, elas logo desafiariam os limites impostos à sua condição de indivíduos e cidadãs, dando visibilidade social e política aos conflitos entre igualdade e hierarquia que jamais deixaram de estar presentes nas práticas públicas e privadas da vida social. Em mais e mais lugares do mundo industrializado, a própria expansão da industrialização, da urbanização, das atividades educacionais, sob os ventos dos princípios universalistas e igualitários da modernidade, faria com que as mulheres invadissem o mundo público da política, da educação superior e do mercado de trabalho, rompendo a dicotomia entre

10. É importante observar que a família conjugal moderna, em nenhum momento e em diferentes contextos nacionais ocidentais, tampouco foi universal, constituindo-se, no entanto, em um modelo normativo, tanto no que se refere aos direitos civis e à legislação familar, quanto no que diz respeito ao imaginário social.

11. Ver, a esse respeito, T. H. Marshall, Cidadania, Classe Social e Status, Rio de Janeiro, Zahar, 1967. 
público e privado. A igualdade no mundo público não conseguiria, contudo, eludir certas barreiras construídas pela hierarquia de gênero sobre a diferença sexual. As experiências derivadas da fisiologia feminina, tais como gravidez, parto, amamentação, foram traduzidas pela construção social e cultural da maternidade e da criação dos filhos como impossibilidades para o cumprimento dos requisitos "universais" da esfera pública. A idéia de universal associou-se ao público/masculino e a de particular ao privado/feminino.

\section{$O$ dilema da igualdade $x$ diferença}

Em uma primeira fase do feminismo, sobretudo europeu e norte-americano, no contexto da luta contra a exclusão pública da mulher e pela ruptura da domesticidade no século XIX, a questão da igualdade entre todos os indivíduos, independentemente do sexo com o qual se nascia, emergiu com força revolucionária. Levantava-se, no campo das relações de gênero, a bandeira de um universalismo que se recusava a colocar no sexo, no corpo, o locus da identidade feminina. Na etapa seguinte, a partir mais ou menos dos anos 60 de nosso século, surgia o feminismo que postulava a diferença radical entre os corpos e as identidades sexuais.

Ao revelar as falácias de uma concepção de igualdade universal que desconsiderava a especificidade do sexo feminino, as feministas contemporâneas transformaram a diferença sexual em uma questão política. Pateman ${ }^{12}$ argumenta que na construção da ordem social moderna, a mulher constituiu-se como uma espécie de modificação do indivíduo, não como um ser distinto: a concepção unitária de indivíduo fundada no mundo público do mercado e da cidadania, embora aparentemente neutra, só conseguiu incorporar a diferença sexual enquanto submissão e adaptação ao modelo masculino. Pateman mostra ainda que nas sociedades modernas a liberdade ainda é considerada uma coisa à parte das relações sexuais, sem conexão com a identidade sexual, com o ser feminino ou o ser masculino: nas sociedades industriais, os movimentos pela liberdade do trabalho, pela democracia, pelo controle dos trabalhadores ou a autogestão ainda possuem uma imagem masculina do trabalhador e a existência de uma esposa fazendo o trabalho doméstico.

12. C. Pateman, The Sexual Contract, Standford, Stanford University Press, 1988. 
Como, nas sociedades modernas, o que conta como cidadania e trabalho ocorre, de fato, no mundo público, muito da igualdade jurídica passou a ser vista como uma questão de as mulheres agirem como homens. O direito ao voto, as reformas antidiscriminatórias em relação a salário e casamento, a descriminalização da prostituição, tudo isto acabou sendo visto como mudanças, permitindo às mulheres tornarem-se cidadãs e proprietárias de suas pessoas - como os homens. Para Pateman, reconstruir a concepção de indivíduo de modo que esta inclua a identidade enquanto um corpo, exige que se abandone a imagem de um indivíduo neutro e unitário baseada na figura masculina e, em lugar disso, abra-se espaço para uma figura masculina e outra feminina. Se o que se aspira é a criação de uma ordem social com liberdade, o corpo e o sexo não deveriam ser ignorados, mas sim diferenciados, em indivíduos de sexo masculino e feminino.

A idéia da diferença veio ocupar um lugar de destaque na agenda política e cultural contemporânea, consistindo em um dos fundamentos para a constituição do gênero enquanto questão propriamente política, assim como para a emergência da mulher enquanto sujeito social. Tornou-se uma espécie de palavra-chave não apenas do feminismo, mas de uma gama variada de movimentos e tendências que, nas últimas décadas e em vários contextos, surgiram como vozes de distintas minorias e categorias sociais combatendo formas específicas de opressão e desigualdade.

Os sujeitos e movimentos sociais que, a partir de meados dos anos 70 , surgiram como parte dessas tendências, vêm, de distintas formas, denunciando os impasses de uma modernidade que limitou sua liberdade e igualdade como mulheres, negros, imigrantes, homossexuais, minorias étnicas etc. Sua emergência política e cultural expressa uma parte dos conflitos entre princípios universais e igualitários e práticas hierárquicas de exclusão social e opressão individual; também evidencia alguns dos limites a que chegaram os processos de modernização.

Turning point do discurso político, a reivindicação da diferença sinaliza o surgimento de novos modos de se perceber a problemática das desigualdades sociais e definir estratégias para enfrentá-las. Modos que não mais reduzem as desigualdades aos efeitos de determinações unívocas e universais, mas que encaram os diferentes conteúdos e formas das desigualdades como o resultado de relações que passam por múltiplos critérios e determinantes, os quais devem ser entendidos em seu significado contextual, histórico e cultural.

Se o universalismo e a igualdade se afirmaram como idéias típicas do pensamento político e filosófico que inaugura a modernidade, a crítica às 
impossibilidades e falácias que tais idéias encobrem institui o eixo do discurso pós-moderno: a heterogeneidade e a pluralidade das identidades sociais não podem ser explicadas por meio de discursos unificadores e universais, os quais acabam se tornando um exercício arbitrário de submissão da diferença - um silenciamento, por detrás da neutralidade, das vozes e desejos de distintas categorias de outros. ${ }^{13}$ Como mostra Lyotard, ${ }^{14}$ a validez heurística e política das filosofias da história e das metanarrativas de legitimação, as quais se pretendem unificadoras do conjunto da experiência humana, legitimando com isso as práticas corretas, são, na condição pós-moderna, colocadas em xeque.

A ênfase no particular, na diferença, ressurge no vocabulário político e filosófico contemporâneo, como parte das transformações sociais, econômicas, políticas, culturais, discursivas que se aceleraram a partir da segunda metade deste século. ${ }^{15}$ Decerto, os diversos conflitos da pós-modernidade ensejam respostas e encaminhamentos dentro de um espectro político e ideológico tão amplo e variado quanto o da modernidade. E é nesse sentido que Hollanda ${ }^{16}$ identifica hoje "pelo menos duas atitudes opostas: uma que procura desconstruir o modernismo para resistir ao status quo, e outra que repudia o modernismo para celebrar o status quo, ou seja, um pós-modernismo de resistência e um pós-modernismo de reação."

É verdade que, se por um lado, privilegiar o universal levou à submissão da diferença, por outro, privilegiar a diferença em detrimento da igualdade pode ter consequiências políticas perigosas, levando ao particularismo e à regressão. Uma perspectiva teórica e política que não desista de formular um projeto de igualdade debate-se, por isso mesmo, na procura de respostas para superar o impasse entre a evidência e a vivência da diferença, e os anseios de igualdade e autonomia ainda longe de terem sido satisfeitos pelo projeto incompleto da modernidade. ${ }^{17}$ Uma questão fundamental que se coloca hoje é: como criticar o que há de falacioso no universalismo, sem no entanto incorrer em um perigo

13. Ver, a esse respeito, F. Lyotard, La Condition Postmoderne, Paris, Éditions de Minuit, 1979; L. Nicholson e N. Fraser, "Social Criticism without Philosophy: An Encounter between Feminism and Postmodernism", in L. Nicholson, ed., Feminism and Postmodernism, Nova Iorque, Routledge, 1990.

14. F. Lyotard, La Condition..., op. cit.

15. Para uma análise das condiçōes econômicas - a acumulaçāo flexível — da pós-modernidade, ver D. Harvey; The Condition of Postmodernity, Oxford, Basil Blackwell, 1989.

16. H. B. de Hollanda, org., Pós-Modernismo e Política, Rio de Janeiro, Rocco, 1991, p. 8.

17. J. Habermas, "Modernity: An Incomplete Project”, in H. Foster, ed., Anti-Aesthetic Essays on Postmodern Culture, Port Towsend, Washington, Bay Press, 1983. 
ainda maior e fortalecer o obscurantismo e o terror que costumam se associar a distintas formas de particularismo, localismo e etnocentrismo? Estas são interrogações que perpassam o fio condutor de alguns embates políticos cruciais da sociedade contemporânea.

Para as mulheres, as aspirações simultâneas de igualdade e diferença costumam instaurar-se como dicotomia e fragmentação interna, como ambigüidade e conflito político, aquilo que Minow ${ }^{18}$ chamou de dilema da diferença. Se, por um lado, ignorar a diferença sexual é o mesmo que adotar uma falsa neutralidade, por outro, ressaltá-la pode aumentar o estigma do desvio. Ou seja, tanto negar quanto afirmar a diferença podem acabar fortalecendo a desigualdade. Este dilema tem acompanhado o feminismo, quer como preocupação teórica, quer como linha divisória para o delineamento de estratégias políticas.

Hoje, o que vem se colocando como algo de maior rèlevância, é buscar caminhos teóricos e políticos capazes de superar a oposição que se estabeleceu entre igualdade e diferença. Ou seja, a crítica desta oposição não pode se limitar a simplesmente inverter seus termos, pois permanecer no âmbito das polaridades dicotômicas não cria alternativas para uma crítica efetiva da hierarquia $\mathrm{e}$ da opressão.

Scott, ${ }^{19}$ ao desconstruir a oposição entre igualdade versus diferença, apresenta uma contribuição importante nesse sentido, situando historicamente, na tradição de Foucault, ${ }^{20}$ os significados dessa dicotomia dentro de um campo discursivo, político. A autora apóia-se também na crítica desconstrucionista de Derrida $^{21}$ à tradição filosófica do pensamento ocidental, o qual se constrói por oposições binárias, cujos primeiros termos adquirem primazia e submetem os segundos: unidade/diversidade; identidade/diferença; presença/falta; univer-sal/específico. Derrida mostrou que o significado das palavras e dos textos não é intrínseco ou fixo, mas deriva de algum contraste implícito ou explícito; as dicotomias não são naturais, mas oposições construídas para fins específicos em contextos particulares.

Reafirmando a necessidade de se contextualizar os significados, para Scott, o debate igualdade versus diferença não passa de uma forma simplista

18. M. Minow, "Learning to Live with the Dilemma of Difference: Bilingual and Special Education" apud J. Scott, "Deconstructing Equality-versus-Difference: Or, the Uses of Post-Structuralism Theory for Feminism”, in M. Hirsch e E. Fox Keller, eds., Conflicts in Feminism, Nova lorque, Routledge, 1990.

19. J. Scott, “Deconstructing Equality...”, op. cit.

20. Ver, por exemplo, M. Foucault, The Archeology of Knowledge, Nova Iorque, Harper e Row, 1976; e História da Sexualidade, Rio de Janeiro, Graal, 1984.

21. J. Derrida, Gramatologia, Sāo Paulo, Ed. Perspectiva, 1973. 
de caracterizar posições e estratégias políticas feministas conflitantes, pois ao constituir-se a partir de uma oposição binária, força uma escolha entre igualdade $o u$ diferença. Opor os dois termos de uma forma antitética esconde sua interdependência, pois igualdade não quer dizer ausência de diferença e diferença não necessita excluir igualdade.

Scott critica o marco conceitual da filosofia ocidental, que representa o mundo em termos de universalismos masculinos e especificidades femininas. Propõe uma teoria que pense as relações sociais não em termos de unidades e universais, mas sim de pluralidades e diversidades; que pense a relação entre igualdade e diferença não como termos intrinsecamente opostos, mas como termos cujos significados devem ser contextualizados.

Se, por um lado, a diferença biológica, sexual, entre homem e mulher, marca, como argumenta Pateman, corpos e identidades distintos, por outro, não podemos cair na armadilha de afirmar que existe uma essência daquilo que é masculino ou feminino, do que é ser homem ou ser mulher. Homens e mulheres distinguem-se enquanto sexos, pois dotados de corpos físicos diferentes, e enquanto gêneros, uma vez que incorporam normas e valores socioculturais que dizem como um homem ou uma mulher devem se comportar. Contudo, atribuir uma qualidade essencial aos homens ou às mulheres impede que se explique tanto a diversidade histórica das culturas masculina e feminina, quanto as variações, escolhas, as pluralidades individuais dentro de um mesmo gênero, em uma determinada configuração históricocultural.

Falar de uma identidade de gênero, seja feminina ou masculina, é problemático, pois os elementos que conformam as identidades de homens e mulheres não são uniformes, variando de acordo com o contexto e o indivíduo. Nesse sentido, seria mais apropriado falar em identidades de gêneroa designação no plural indicando a diversidade dos sujeitos. Por exemplo, no Brasil contemporâneo, para muitas mulheres pertencentes a segmentos médios urbanos, a maternidade e, mais ainda, o casamento, não se configuram hoje como $o$ eixo de suas identidades. ${ }^{22}$

É nessa mesma perspectiva que entendo a análise de Costa ${ }^{23}$ sobre a polaridade que os discursos científico e popular instituíram entre heterossexualidade e homossexualidade. Assim como Scott apontou os limites de se

22. Ver, por exemplo, A. C. Lo Bianco, “A Psicologizaçāo do Feto”, in S. Figueira, org., Cultura da Psicanálise, São Paulo, Brasiliense, 1985; J. Vaitsman, Flexiveis e Plurais..., op. cit.

23. J. F. Costa, A Inocência e o Vício - Estudos sobre o Homoerotismo, Rio de Janeiro, Relume-Dumará, 1992. 
falar em uma identidade de gênero, Costa, com base em dados empíricos que ele e Parker ${ }^{24}$ levantaram, argumenta que não existe algo como um homossexualismo comum a todos os que se identificam ou se auto-rotulam como homossexuais. Em vez disso, dentro da categoria de homossexuais existe uma grande variedade de características psíquicas, sexuais e sociais e uma variedade igualmente grande de práticas, condutas e desejos, o que dificulta sua tipificação, seja pelo observador ou por parte do próprio sujeito.

Preferindo seguir Ferenczi, ${ }^{25}$ Costa utiliza o termo homoerotismo para designar a inclinação da atração pelo mesmo sexo. Reafirmando a idéia desconstrucionista de que não existe uma sexualidade e um tipo humano homossexuais independentes do hábito lingüístico e da configuração histórica que os criou, Costa analisa a dicotomia heterossexualidade/homossexualidade como parte do vocabulário da mesma ciência médica do século XIX e das relações sociais que produziram o indivíduo moderno, a cultura do público $\mathrm{x}$ privado, do masculino $\mathrm{x}$ feminino. Ou seja, do "complexo prático-discursivo que, pondo a família conjugal e a sexualidade reprodutiva como centro da identidade do indivíduo burguês, realçou o valor da sexualidade na definição dessa identidade, criando ao mesmo tempo, o código da norma e do desvio sexual". ${ }^{26}$

Costa acentua a historicidade e a contextualidade dos significados da identidade sexual, a qual se organiza a partir de categorias inventadas e estabelecidas no século XIX e que descrevem, por meio de contrastes, o que deveria ser um homem heterossexual, ou, como ele não deveria nem poderia ser: "O 'homossexual', por conseguinte, era o homem que não podia ser pai; não podia ser marido; não podia ser o bom cidadão e não poderia representar adequadamente a norma moral de conduta do burguês civilizado, metropolitano, e racialmente superior aos povos inferiores ou às classes subalternas." 27

24. Os trabalhos de R. Parker citados por Costa, sāo: "Youth, Identity and Homossexuality: The Changing Shape of Sexual Life in Contemporary Brazil”, Journal of Homossexuality, vol. 17, $n^{2} 3$ e 4, 1989; "Bodies and Pleasures: On the Construction of Erotic Meanings in Contemporary Brazil, Anthropology and Humanism Quarterly”, vol. 14, $\mathrm{n}^{\circ} 2,1989$; Bodies, Pleasures and Passions - Sexual Culture in Contemporary Brazil, Boston, Beacon Press, 1990.

25. A referência da obra citada por Costa é: S. Ferenczi, “L’Homoerotisme: Nosologie de l'Homosexualité Masculine”, in Oeuvres Complètes, tomo II: 1912-1919, Psychanalyse II, Paris, PUF, 1970.

26. J. F. Costa, A Inocência e o..., op. cit., p. 134.

27. Idem, p. 156 (ênfases do autor). 
Além dos pobres e primitivos, está faltando uma outra categoria de seres que não representam o universal - as mulheres —, que o burguês, branco e heterossexual, deve subjugar. Não só o indivíduo-homem é o detentor das qualidades morais universais - igualdade e autonomia - adquiridas pela sua posição na esfera pública, mas para que seu papel seja desempenhado a contento, ele deve tornar-se um heterossexual, marido e pai. Os atributos morais de igualdade e autonomia do indivíduo-burguês masculino são complementados, compulsoriamente, por todo um conjunto de atributos psíquicos, afetivos e comportamentais, que também acabam se tornando parte da essência ou natureza masculina, em contraposição aos atributos psíquicos, afetivos e comportamentais que então se associam à essência ou natureza feminina.

No que se refere à inclinação erótica, também é problemático falar em identidade homossexual, uma vez que as pluralidades mediante as quais podem se desdobrar as identidades individuais não conseguem ser explicadas por categorias que reduzem sua complexidade e ignoram seus significados culturais e individuais.

Nem a diferença entre os indivíduos segundo o sexo nem segundo o gênero explicam, de forma unívọca, as diferenças, as possibilidades infinitas do sentir e das ações humanas: a experiência que se tem dos corpos biológicos e dos corpos sociais, de si e do outro, não existe fora de certos contextos históricos e simbólicos, estes últimos englobando tanto os significados construídos coletiva e conflitivamente por meio da cultura, quanto aqueles atribuídos e vividos pelo sujeito dentro de tais contextos.

Essa discussão não se restringe à questão do gênero ou à da sexualidade, que são apenas dois dentre os inúmeros exemplos da submissão lingüística da diversidade humana - social, cultural, individual - pelas categorias universais e essencialistas. Tendo em vista a construção de novos caminhos teóricos e políticos para se lidar com a problemática da desigualdade, a alternativa que se coloca, consiste, na palavras de Scott, “[...] recusar opor igualdade e diferença e insistir continuamente nas diferenças - diferenças como a condição para identidades coletivas e individuais, diferenças como o desafio constante à imobilidade dessas identidades, a história como a ilustração repetida do jogo das diferenças, diferenças como o próprio significado da igualdade". 28

Não se trata então, simplesmente, de se deter no momento mesmo em que se resgata a especificidade de um indivíduo-feminino. Continuar esse mo-

28. J. Scott, “Deconstructing Equality...”, op. cit., p. 144. 
vimento e falar, não tanto de diferença, mas de diferenças, tanto do ponto de vista teórico quanto político, significa reconhecer que indivíduos de sexo feminino e masculino - e seus comportamentos, identidades, escolhas, desejos - existem enquanto pluralidades complexas e irredutiveis umas às outras.

Se quisermos avançar na compreensão dos determinantes e dos conteúdos̀ das iniqüidades sociais e em saúde, é preciso enfrentar o desafio de incorporar em nossas teorias os significados contextuais das categorias que utilizamos e construir uma metodologia que nos permita revelá-los.

\section{Contextualizando significados: possibilidades para pensar gênero e saúde}

Na primeira parte deste artigo, procurei mostrar que para superar o dilema teórico e político que obriga à escolha entre, por exemplo, igualdade ou diferença, homossexualidade ou heterossexualidade, é necessário um movimento com uma dupla dimensão. A primeira consiste em admitir a natureza histórica e contingente das categorias analíticas, o que, de imediato, instaura a necessidade de contextualização de seus significados; a segunda está ligada à primeira e vê o social enquanto pluralidades — de sujeitos, identidades sociais, interesses, necessidades.

Imaginando que diferentes formas de iniqüidade poderiam ser minoradas se houvesse uma melhor distribuição do poder social e econômico, vejamos como a perspectiva discutida pode orientar a interpretaçāo de alguns tipos de iniqüidades em saúde.

$\mathrm{Na}$ área da saúde reprodutiva, as condições de informação, o acesso e as possibilidades legais em relação ao aborto e a diferentes procedimentos contraceptivos, costumam ser sistematicamente submetidos a discursos universais que procuram legitimar as práticas corretas nesta área. Propostas e políticas, ao definirem seus alvos mediante palavras de ordem como planejamento familiar, controle da natalidade, segurança nacional, direito à vida, intervenção imperialista, expressam muito mais posições e disputas políticas e ideológicas do que as necessidades das próprias mulheres.

Em outra direção, ao tratar a contracepção como um direito reprodutivo, isto é, como um direito individual e de cidadania, o movimento feminista contextualizou essa questão do ponto de vista do sujeito, das mulheres enquanto indivíduos. Nem o aborto nem as diferentes formas de contracepção, inclusive a esterilização, possuem quaisquer significados intrínsecos 
ou fixos, pois as necessidades não são as mesmas para todas as mulheres, nem mesmo o são para uma mesma mulher ao longo de sua trajetória de vida. As necessidades contraceptivas das mulheres, além de vincularem-se aos conteúdos específicos de suas identidades, dependem de certos contextos, da situação de vida em que se encontram.

Uma outra questão importante no campo da saúde é o fato de que as iniqüidades se desenvolvem como parte de certos sistemas sociais $e$ simbólicos, dentro dos quais diferenças e hierarquias entre determinadas categorias sociais são construídas. Isto leva muitas vezes a que sujeitos diferentes, que possuem uma posição inferior no sistema simbólico, se constituam como alvo privilegiado da opressão e da intolerância. Iniqüidades em saúde bastante evidentes sob esse ângulo são os fenômenos de morte e morbidade derivados das distintas formas de violência contra os de outro sexo, inclinação erótica, etnia, raça, religião. A opressão da diferença, e a recusa a considerar o diferente enquanto igual em direitos e liberdade, ao colocar-se como um dos problemas centrais da agenda cultural e política contemporânea, não pode mais deixar de constituir um dos objetivos das políticas de combate às iniqüidades.

No que se refere especificamente à violência contra a mulher, pesquisas recentes vêm revelando que na América Latina esta é, em grande parte, uma violência privada, exercida no interior da própria família. A título de exemplo: no Brasil, entre janeiro e junho de 1989, na região da Baixada Fluminense, no Rio de Janeiro, $47 \%$ dos crimes cometidos contra as mulheres e registrados nas delegacias de polícia foram perpetrados por maridos, companheiros, namorados, noivos e ex-maridos, ou seja, pelos próprios membros do círculo familiar. ${ }^{29}$

No âmbito do mercado de trabalho e da previdência social, a hierarquia de gênero também afeta, como assinalam De los Ríos e Gómez, ${ }^{30}$ as condições de saúde e bem-estar das mulheres. A definição legal de trabalho como requisito de acesso à prestação de saúde e seguridade social, embora aparentemente neutra, na prática exclui de seus benefícios um número maior de mulheres do que de homens, ao desconsiderar o trabalho doméstico não remunerado e as ocupações do setor informal, que aglutinam um número muito maior de mulheres do que de homens. As menores taxas de emprego

29. Violência contra a Mulher, Rio de Janeiro, UFRJ/ENSP-Fiocruz/CEPEBA, s/d.

30. R. de los Ríos e E. Gómez, La Mujer en la Salud y el Desarrollo: Un Enfoque Alternativo, Nova Iorque, Fourth International Women's Conference, University of Rochester, 1991, mimeo. 
feminino no setor formal da economia, a descontinuidade da participação no trabalho assalariado associada à maternidade e a menor remuneração do trabalho recebida pela mulher em comparação com o homem produz, na velhice, menor proteção assistencial para as mulheres.

Essas iniqüidades sociais e em saúde vinculam-se nitidamente à dicotomia entre público/privado e à concepção de indivíduo neutro que não abriu espaço para a diferença sexual. Como na tradição da modernidade os direitos de igualdade e liberdade consubstanciaram-se na esfera pública do mercado e da política, as restrições para que as mulheres possam, de fato, exercer seus direitos de modernidade, têm sido grandes. As conquistas da igualdade universal da cidadania obscureceram o fato de que as práticas que tradicionalmente vieram a ser exercidas pelas mulheres no mundo moderno fora do mercado e da regulação pública, não conseguiram ser incorporadas pelo universalismo do mundo público e masculino.

Contextualizar o que as conquistas da modernidade significaram para distintas categorias de mulheres, permite perceber os limites que lhes foram impostos pelos próprios pressupostos históricos e culturais dentro dos quais tais conquistas foram alcançadas. Nas sociedades latino-americanas, onde também assistimos a um desmoronar do discurso universalista e das categorias binárias, integrar as diferenças na reconstrução do conceito de igualdade tem seus próprios desdobramentos no interior dos respectivos contextos nacionais e locais. O que se percebe como tendência é que se, por um lado, ainda estamos longe de termos conquistado os direitos de uma modernidade que não conseguiu se compatibilizar com a modernização, por outro, ao fazermos a crítica de suas exclusões já começa a se falar a linguagem de um pós-modernismo de resistência. Nessa narrativa, o masculino e o feminino não se colocam como polaridades hierárquicas: o indivíduo pode desdobrarse, flexivelmente, em homem e mulher, e, rompendo com os pressupostos do que deve ser um homem ou uma mulher, deixa a individualidade aflorar enquanto espaço de autonomia.

\section{RESUMO}

\section{Hierarquia de Gênero e Iniqüidade em Saúde}

O artigo problematiza a utilização de categorias universais na análise dos fenômenos sociais e propõe que se proceda a uma contextualização histórica e culutural dos significados de tais categorias: Parte-se de uma crítia à 
concepção de indivíduo neutro e universal que, por intermédio das idéias de igualdade e autonomia, constitui o eixo dos valores ocidentais modernos. $O$ argumento principal é que as idéias de igualdade e autonomia se conformaram historiamente como atributos do sexo masculino. Isto porque na gênese do indivíduo moderno não houve espaço para que a diferença sexual se expressasse de forma igualitária, traduzindo-se, ao contrário, por meio de uma dicotomia entre público e privado atribuída segundo o gênero. A ruptura desta dicotomia por parte das mulheres é vista como parte da emergência dos novos sujeitos sociais, que colocam na agenda política e cultural ccontemporânea a idéia da diferença. Em seguida, examina-se, com base em alguns autores, a necessidade de superar o dilema teórico e político que reduz a complexidade das relações sociais a polaridades dicotômicas. Finalmente, utiliza-se a perspectiva discutida para mostrar como a hierarquia de gênero expressa-se mediante a dicotomia público/privado e a concepção de indivíduo neutro vincula-se a alguns tipos de iniqüidades em saúde.

\section{ABSTRACT}

\section{Gender Hierarchy and Health Iniquity}

The article questions the use of universal categories in analyzing social phenomena and proposes that the significances of such categories be placed into a historical and cultural context. The basis for this discussion is a criticism of the concept of the neutral, universal individual who, through the ideas of equality and autonomy forms the axis of modern Western values.

The main argument is that the ideas of equality and autonomy have historically gained shape as attributes of the male sex. This is because the genesis of the modern individual precluded an egalitarian expression of sexual difference, which instead found translation in a sex-assigned dichotomy between the public and the private spheres. Women are now breaking the boundaries of this dichotomy as part of the emergence of new social subjects, who have placed the idea of "difference" on the contemporary political/cultural agenda. Drawing support from a number of authors, the article moves on to discuss the need to overcome the theoretical and political dilemma that reduces the complexity of social relations to dichotomous polarities. Lastly, from this perspective it is shown how the gender hierarchy manifest in the public/private dichotomy and in the 
concept of the neutral individual is related to certain types of iniquities in the realm of health care.

\section{RÉSUMÉ}

\section{Hierarchie de Genre et Inégalité dans le Domaine de la Santé}

L'article aborde diverses questions liées à l'utilisation de catégories universelles pour l'analyse des phénomènes sociaux et propose de situer les significations de ces catégories dans leur contexte historique et culturel. Le point de départ est une critique de la conception d'individu neutre et universel qui, par l'intermédiaire des idées d'égalité et d'autonomie, constitue l'axe principal des valeurs occidentales modernes. L'argument majeur est que les idées d'égalité et d'autonomie sont devenues au cours de l'histoire des attributs du sexe masculin. Ceci parceque au cours de la génèse de l'individu moderne, la différence sexuelle n'a pu s'exprimer de manière égalitaire. Au contraire, cette différence s'est traduite par une dichotomie entre public et privé attribuée suivant le genre. Le fait que les femmes aient rompu cette dichotomie est perçu comme l'émergence partielle de sujets sociaux nouveaux, qui introduisent l'idée de "différence" dans l'agenda politique et culturel contemporain. A l'aide de quelques auteurs, la discussion se poursuit sur la nécessité de dépasser le dilemme théorique et politique qui réduit la complexité des relations sociales à des polarités dichotomiques. Finalement, la perspective de la discussion permet de montrer comment la hiérarchie de genre exprimée au moyen de la dichotomie public/privé ainsi que par l'idée de neutralité de l'individu, a un lien avec divers types d'inégalités dans le domaine de la santé. 